\title{
Green synthesis of silver nanoparticles using cranberry powder aqueous extract: characterization and antimicrobial properties
}

This article was published in the following Dove Press journal:

International Journal of Nanomedicine

I December 2015

Number of times this article has been viewed

\author{
Asmaa A Ashour' \\ Dina Raafat ${ }^{2}$ \\ Hanan M El-Gowelli3 \\ Amal H El-Kamel' \\ 'Department of Pharmaceutics, \\ ${ }^{2}$ Department of Pharmaceutical \\ Microbiology, ${ }^{3}$ Department of \\ Pharmacology and Toxicology, Faculty \\ of Pharmacy, Alexandria University, \\ Alexandria, Egypt
}

Background: The growing threat of microbial resistance against traditional antibiotics has prompted the development of several antimicrobial nanoparticles (NPs), including silver NPs (AgNPs). In this article, a simple and eco-friendly method for the synthesis of AgNPs using the cranberry powder aqueous extract is reported.

Materials and methods: Cranberry powder aqueous extracts $(0.2 \%, 0.5 \%$, and $0.8 \% \mathrm{w} / \mathrm{v})$ were allowed to interact for 24 hours with a silver nitrate solution $(10 \mathrm{mM})$ at $30^{\circ} \mathrm{C}$ at a ratio of 1:10. The formation of AgNPs was confirmed by ultraviolet-visible spectroscopy and their concentrations were determined using atomic absorption spectroscopy. The prepared NPs were evaluated by transmission electron microscopy, measurement of $\zeta$-potential, and Fouriertransform infrared spectroscopy. The in vitro antimicrobial properties of AgNPs were then investigated against several microbial strains. Finally, in vivo appraisal of both wound-healing and antimicrobial properties of either plain AgNPs (prepared using 0.2\% extract) or AgNPPluronic F-127 gel was conducted in a rat model after induction of a Staphylococcus aureus ATCC 6538P wound infection.

Results: The formation of AgNPs was confirmed by ultraviolet-visible spectroscopy, where a surface-plasmon resonance absorption peak was observed between 432 and $438 \mathrm{~nm}$. Both size and concentration of the formed AgNPs increased with increasing concentration of the extracts. The developed NPs were stable, almost spherical, and polydisperse, with a size range of $1.4-8.6 \mathrm{~nm}$. The negative $\zeta$-potential values, as well as Fourier-transform infrared spectroscopy analysis, indicated the presence of a capping agent adsorbed onto the surface of the particles In vitro antimicrobial evaluation revealed a size-dependent activity of the AgNPs against the tested organisms. Finally, AgNPs prepared using 0.2\% extract exhibited a substantial in vivo healing potential for full-thickness excision wounds in rats.

Conclusion: AgNPs were successfully synthesized from a silver nitrate solution through a simple green route, using cranberry powder aqueous extract as a reducing as well as capping agent.

Keywords: cranberry, silver nanoparticles, antimicrobial properties, wound healing

\section{Introduction}

The growing ineffectiveness of traditional antibiotics and the continuous emergence of resistance among target microorganisms has become a common phenomenon. In this context, several classes of antimicrobial nanoparticles (NPs) and nanosize carriers for antibiotic delivery have proven their effectiveness for the treatment of infectious diseases, including antibiotic-resistant ones, both in in vitro and in animal models. ${ }^{1}$

Among the various types of metallic NPs, silver NPs (AgNPs) have proven to be the most effective against bacteria and viruses. ${ }^{1}$ In addition, microbes are unlikely to develop resistance against silver, because the metal attacks a broad range of target
Department of Pharmaceutics, Faculty of Pharmacy, Alexandria University,

I Khartoum Square, Azarita, Alexandria, 21521, Egypt

Tel +201005080510

Fax +2034873273

Email amalelkamel@yahoo.com 
sites in the organisms. ${ }^{2}$ AgNPs target both the respiratory chain and the cell-division machinery, while concomitantly releasing silver ions $\left(\mathrm{Ag}^{+}\right)$that enhance bactericidal activity, finally leading to cell death. ${ }^{3}$ The antimicrobial activity of AgNPs depends on their size ${ }^{4}$ and shape. ${ }^{2}$ Diverse applications of AgNPs include wound dressings, coating for medical devices and surgical masks, woven fabric microfiltration membranes, and nanogels. ${ }^{5-8}$

There are different approaches for the synthesis of AgNPs; however, chemical and physical syntheses have many drawbacks. These methods mostly depend on the use of toxic and highly reactive reagents, thus posing a risk to the environment and humans. Moreover, these procedures are too expensive to be of industrial value. ${ }^{3}$ Therefore, the green synthesis of stable AgNPs with controlled size and shape is a very lucrative approach. As a result, some novel methods have recently been developed using either microbes (such as bacteria and fungi) ${ }^{9}, 10$ or plant extracts (from seeds, leaves, and tubers $)^{11-13}$ for the synthesis of AgNPs.

The use of plants for AgNPs synthesis is preferred over other biological processes for several reasons: 1) it is less expensive, 2) it could be suitably scaled up for large-scale NP synthesis, 3 ) it avoids the elaborate process of maintaining a cell culture, ${ }^{14}$ and 4 ) plant extracts possess many antioxidants, which act as reducing as well as capping agents. ${ }^{15}$

Cranberry fruit was used as extract powder that was standardized to contain not less than $5 \%$ of anthocyanidins. Cranberry fruit has a diverse phytochemical profile that included three classes of flavonoids (flavonols, anthocyanins, and proanthocyanidins), catechins, hydroxycinnamic and other phenolic acids, and triterpenoids. ${ }^{16}$ All polyphenolic compounds present in the extract can act as both reducing and capping agents for the prepared particles.

The proposed mechanism of formation of AgNPs using plant phytochemicals can proceed through three steps: first, charge transfer from reducing agents to $\mathrm{Ag}^{+}$results in the formation of $\mathrm{Ag}$ atoms, which subsequently nucleate to form small AgNPs; second, a condensation step occurs in which small particles grow to form larger ones, followed by surface reduction of any $\mathrm{Ag}^{+}$present on the surface of the formed NPs; and third, adsorption of excess negatively charged reducing agents ions on the surface of the formed particles, achieving electrostatic stabilization and thus controlling their sizes. Steric hindrances arising from the large capping molecules result in further stability in the size of the AgNPs. ${ }^{17}$

Puišo et $a{ }^{18}$ prepared AgNPs using cranberry juice by ultraviolet (UV) irradiation; they proved that AgNPs could potentially be used for food preservation in the form of antimicrobial food packaging. However, the prepared NPs were unstable, wherein the silver colloidal solution underwent discoloration after 12 hours.

The current study demonstrates the simple green synthesis of AgNPs through the reduction of an aqueous $\mathrm{AgNO}_{3}$ solution using an cranberry powder aqueous extract $(\mathrm{Cr})$. Cranberry was selected for AgNPs synthesis because it possesses large amounts of natural antioxidants, which can serve as both reducing and capping agents. The developed particles were characterized in vitro in terms of size, shape, concentration, UV-visible (UV-vis) absorption pattern, and Fourier-transform infrared spectroscopy (FT-IR). In vitro estimation of their antimicrobial activity against a range of organisms and in vivo evaluation of NPs displaying optimum in vitro characteristics were also performed.

\section{Materials and methods \\ Materials}

Cranberry (Vaccinium macrocarpon, family Ericaceae) dried extract powder, standardized to contain not less than 5\% anthocyanidins, was kindly provided by EMA Pharm Pharmaceuticals (Cairo, Egypt). The following chemicals were obtained from their respective companies: silver nitrate (Winlab Ltd., Market Harborough, UK); sodium hydroxide (Adwic; El-Nasr Pharmaceutical Chemicals Co, Cairo, Egypt); nitric acid (El-Gomhouria Pharmaceutical Co, Cairo, Egypt); 1,1-diphenyl, 2-picrylhydrazyl (DPPH) radical (Sigma-Aldrich Co, St Louis, MO, USA); Mueller-Hinton broth, (Oxoid Ltd, Basingstoke, UK); Pluronic F-127 (BASF SE, Ludwigshafen, Germany); thiopental sodium injection (Novartis International AG, Basel, Switzerland); and cetrimide-chlorhexidine solution (Novartis).

\section{Preparation of cranberry powder aqueous extract}

$\mathrm{Cr}(0.2,0.5$, and $0.8 \% \mathrm{w} / \mathrm{v})$ was prepared by adding the dried extract to $50 \mathrm{~mL}$ distilled deionized water (DDW). The mixture was stirred for 30 minutes and then filtered through Whatman grade 1 filter paper. The $\mathrm{pH}$ of the extract was adjusted to 6 using $0.01 \mathrm{M} \mathrm{NaOH}$.

\section{Synthesis of AgNPs}

An aliquot of $1 \mathrm{~mL}$ of $\mathrm{Cr}$ was added to $10 \mathrm{~mL}$ of $10 \mathrm{mM}$ $\mathrm{AgNO}_{3}$ solution. The mixture was shaken at 100 strokes per minute in a water bath in the dark for 24 hours at $30^{\circ} \mathrm{C}$. The prepared AgNPs were purified by centrifugation at 
20,000 rpm for 1 hour at $4^{\circ} \mathrm{C}$ using a refrigerated centrifuge (3K 30; Sigma Laborzentrifugen GmbH, Osterode am Harz, Germany). The supernatant was removed, and the precipitate was redispersed in DDW by sonication for 1 minute, and then centrifuged again at $20,000 \mathrm{rpm}$ for 1 hour at $4^{\circ} \mathrm{C}$. The washing procedure was repeated three times.

\section{In vitro determination of free radical scavenging activity cranberry powder aqueous extracts}

The antioxidant activity of different concentrations of Crs against the DPPH radical was evaluated using a spectrophotometric assay, as previously described. ${ }^{19}$ Briefly, an aliquot $(400 \mu \mathrm{L})$ of appropriately diluted extract was mixed with 2 $\mathrm{mL}$ DPPH solution $(0.02 \mathrm{mg} / \mathrm{mL})$. Samples were kept in the dark for 15 minutes at room temperature, and then the absorbance (Abs) was measured at $517 \mathrm{~nm}$. Control samples containing the solvent and DPPH were concomitantly prepared, and their respective Abs was measured. The percentage of Abs reduction at $517 \mathrm{~nm}$ due to the decolorization of the deep-violet DPPH solution was calculated using the following equation:

$$
\underset{\text { in Abs }}{\% \text { reduction }}=\frac{\text { Abs control }- \text { Abs sample }}{\text { Abs control }} \times 100
$$

The extent of decolorization was determined as a function of concentration, and calculated relative to the equivalent ascorbic acid concentration $(0.005-0.015 \mathrm{mg} / \mathrm{mL})$. The radical scavenging activity was expressed in milligrams of ascorbic acid equivalent (AAe) to the amount of reducing agents in $1 \mathrm{~mL}$ plant extract (mg AAe $/ \mathrm{mL})$.

\section{Determination of the concentration of the prepared AgNPs using atomic absorption spectroscopy}

The assay was performed according to the method described previously by Salem et al ${ }^{20}$ with slight modifications. The dispersions of AgNPs were treated with concentrated nitric acid $(69 \%)$ at a ratio of $1: 1$ in a sand bath at $120^{\circ} \mathrm{C}$ for 90 minutes to ensure complete solvation of AgNPs into $\mathrm{Ag}^{+}$. The silver concentration was measured after appropriate dilution in DDW by air-acetylene flame using a silver flame. The fuel-flow rate was set at $0.9-1.2 \mathrm{~L} / \mathrm{min}$, and the atomization temperature was $1,100^{\circ} \mathrm{C}$. The device was calibrated using a $3 \mu \mathrm{g} / \mathrm{mL}$ standard solution of metallic silver dissolved in $5 \%$ nitric acid.
Morphological examination and particlesize measurement by transmission electron microscopy

Samples to be examined by transmission electron microscopy (TEM) were prepared by placing a drop of the NP dispersion in DDW onto a carbon-coated copper grid; they were then allowed to dry under ambient conditions. The average size of the particles was measured, and the polydispersity index (PDI) was calculated.

\section{Measurement of $\xi$-potential}

The prepared AgNP formulations were subjected to $\xi$-potential analysis by photon-correlation spectroscopy using a Zetasizer Nano ZS (Malvern Instruments, Malvern, UK). $\xi$-Potential measurements were performed at $25^{\circ} \mathrm{C}$ with an incident wavelength of $633 \mathrm{~nm}$ and a $173^{\circ}$ back-scattering angle. The viscosity, refractive index (RI), and absorption values were provided by the Malvern software for water $(\mu=0.8872 \mathrm{cP}, \mathrm{RI}=0.135)$ and crystalline silver $(\mathrm{RI}=1.3330$, absorption $=3.987$ ).

\section{UV-vis absorbance spectroscopy}

The reduction of $\mathrm{Ag}^{+}$was monitored by measuring the $\mathrm{UV}$-vis spectrum using a UV-160A double-beam spectrophotometer (Shimadzu, Kyoto, Japan). The spectrum was recorded throughout a range of $300-800 \mathrm{~nm}$, and the wavelength corresponding to maximum absorption was determined.

\section{Fourier-transform infrared spectroscopy}

AgNPs prepared using $\mathrm{Cr} 0.8 \%$ and the corresponding extract were respectively freeze-dried (Cryodos freeze-dryer; Telstar Industrial SL, Terrassa, Spain). The dried samples were mixed in a mortar with $\mathrm{KBr}$ and compressed into disks. The samples were scanned at $500-4,000 \mathrm{~cm}^{-1}$ using an FT-IR spectrometer (Perkin Elmer Inc, Waltham, MA, USA).

\section{Evaluation of the in vitro antimicrobial activity of AgNPs}

Five microbial strains were used, comprising three standard strains (Staphylococcus aureus [ATCC 6538P], Pseudomonas aeruginosa [ATCC 9027], and Candida albicans [ATCC 2091]) and two clinical isolates: a methicillin-resistant $S$. aureus obtained from an infected wound and a multidrugresistant $P$. aeruginosa isolated from blood. The sensitivity of the test organisms to the prepared AgNPs was assessed by determining the minimum inhibitory concentration (MIC) using broth macrodilution. ${ }^{21}$ The MIC value was defined as the lowest concentration of AgNPs resulting in complete 
inhibition of visible microbial growth after 24-48 hours of incubation at $37^{\circ} \mathrm{C}$, under conditions that allowed confluent growth of the respective test strain in control test tubes, lacking AgNPs.

The minimum lethal concentration (MLC) was assigned by inoculating $100 \mu \mathrm{L}$ aliquots from test tubes showing absence of microbial growth after 48 hours of incubation at $37^{\circ} \mathrm{C}$ into $5 \mathrm{~mL}$ MHB (for bacteria) or glucose broth (for yeast). The samples were incubated at $37^{\circ} \mathrm{C}$ for 24 and 48 hours for bacteria and fungi, respectively. The MLC was defined as the lowest concentration of the antimicrobial agent that prevented microbial regrowth.

\section{Study of bacterial killing kinetics}

To examine the killing kinetics of AgNPs, $P$. aeruginosa ATCC 9027 and $S$. aureus ATCC 6538P were used as test organisms. An aliquot of $200 \mu \mathrm{L}$ of the overnight culture of each organism was separately transferred into $20 \mathrm{~mL}$ of double-strength MHB (dsMHB), and the subcultures were incubated in a shaking water bath at $37^{\circ} \mathrm{C}$ until the exponential phase (optical density at $600 \mathrm{~nm}$ wavelength of around 0.5) was reached. Aliquots of these respective subcultures were diluted with dsMHB to obtain a starting inoculum of approximately $2 \times 10^{6} \mathrm{CFU} / \mathrm{mL}$. An aliquot of $5 \mathrm{~mL}$ of AgNPs (at a final concentration of $2 \times$ MIC) prepared using $\mathrm{Cr} 0.2 \%$ was added to an equal volume of the inoculated dsMHB. An appropriate control, where AgNPs were replaced with sterile DDW, was run alongside the experiment. The flasks were incubated in a shaking water bath at $37^{\circ} \mathrm{C}$. Samples were removed at 0, 1, 2, 3, 4, 5, 6, and 24 hours for viable count estimations. Killing curves were constructed by plotting the number of survivors $\left(\log _{10}\right.$ $\mathrm{CFU} / \mathrm{mL}$ ) against time over a period of 24 hours. Experiments were performed in duplicate.

\section{Evaluation of the effect of AgNPs on bacterial cell structure using scanning electron microscopy}

An aliquot of $200 \mu \mathrm{L}$ from the overnight culture of the test organisms was separately transferred into $20 \mathrm{~mL}$ of dsMHB. We proceeded as previously described to prepare dsMHB containing a starting inoculum of approximately $2 \times 10^{6} \mathrm{CFU} / \mathrm{mL}$. AgNP dispersion $(1 \mathrm{~mL})$ prepared using $\mathrm{Cr} 0.2 \%$ (at a final concentration of $2 \times \mathrm{MIC}$ ) was added to a sterile test tube containing an equal volume of the inoculated dsMHB. An appropriate control, where AgNPs were replaced with sterile DDW, was run alongside the experiment. Test tubes were incubated in a shaking water bath at $37^{\circ} \mathrm{C}$ for 3.5 hours ( $P$. aeruginosa) and 8 hours (S. aureus). The samples were subsequently fixed by adding $4 \mathrm{~F}: 1 \mathrm{G}$ reagent (4\% formaldehyde and $1 \%$ glutaraldehyde) in phosphate-buffered saline $(\mathrm{pH} 7.2)$, at a ratio of $1: 1$, in order to preserve the bacterial structure during the following preparation steps. The samples were stored overnight at $4^{\circ} \mathrm{C}$, and then centrifuged at 3,000 rpm for 15 minutes. The bacterial pellet was washed twice with phosphate-buffered saline ( $\mathrm{pH} 7.2$ ), followed by a dehydration process using $30 \%, 50 \%$, and $70 \%$ ethanol. The fixed cells were mounted on a glass slide, and then dried and gold-coated, to allow observation of the morphology of the bacterial cells using scanning electron microscopy (SEM).

\section{Preparation of AgNP-Pluronic F-I 27 thermosensitive gel}

A 25\% w/v of Pluronic F-127 gel containing AgNPs prepared using $\mathrm{Cr} 0.2 \%$ was formulated. The concentration of the NPs was set at $91.5 \mu \mathrm{g} / \mathrm{mL}$, which was equivalent to five times the MIC value of the test organism. The mixture was refrigerated at $4^{\circ} \mathrm{C}$ and stirred periodically until a clear solution was obtained. The solution was then left overnight in the refrigerator. For comparison, a plain gel without AgNPs was prepared.

\section{Experimental animals}

The experimental animals used were male albino rats of 6 months' age, weighing $200 \pm 10 \mathrm{~g}$ (maintained at the animal house of the Faculty of Pharmacy, Alexandria University, Egypt). Rats, housed individually in cages, were kept at an ambient temperature and given free access to rat chow $(16 \%$ protein; Tanta Oil and Soap Co, Tanta, Egypt) and water. The cages were swabbed periodically throughout the study with hot diluted Savlon and rinsed thoroughly. Experiments were performed in strict accordance with the guidelines of the Institutional Animal Care and Use Committee (Faculty of Pharmacy, Alexandria University, Egypt, permit 29) who also approved this study. Surgery was performed under thiopental anesthesia, and all efforts were made to minimize suffering.

\section{In vivo evaluation of the antimicrobial and wound-healing properties of AgNP- Pluronic F-I 27 gel}

Three preparations were subjected to in vivo evaluation, namely: 1) plain Pluronic F-127 gel, 2) AgNP (Cr 0.2\%)loaded Pluronic F-127 gel, and 3) AgNP dispersion. Their antimicrobial and wound-healing potential were assessed 
in heavily infected full-thickness wounds (inoculated with $50 \mu \mathrm{L}$ of $S$. aureus culture, $10^{6} \mathrm{CFU} / \mathrm{mL}$ ) in a rat model for 13 days. Wound healing was evaluated morphologically, microbiologically, and histologically.

Rats were weighed and anesthetized with an intraperitoneal (IP) injection of thiopental sodium $(50 \mathrm{mg} / \mathrm{kg}$ body weight). The dorsal and lateral areas of the skin of the rats were shaved with an electric animal clipper (Oster Golden A5; Jarden Corporation, Boca Raton, FL, USA). The skin was prepared by scrubbing with a dilute solution of cetrimide-chlorhexidine (1:30) followed by $70 \%$ ethanol. Wound disinfection and all other surgical procedures were performed under anesthesia using thiopental sodium (50 mg/kg, IP).

Two standardized full-skin-thickness circular excision wounds of an initial diameter of $10 \pm 1 \mathrm{~mm}$ were generated on the shaved back of each rat parallel to the vertebral column by marking using skin-marking ink (Delasco ${ }^{\circledR}$; Dermatologic Lab \& Supply Inc, Council Bluffs, IA, USA) and then surgically removing the marked circles. All excisions were infected by careful instillation of an inoculum of $50 \mu \mathrm{L}$ from an overnight culture of the test organism $\left(\sim 10^{6} \mathrm{CFU} / \mathrm{mL}\right)$ using a micropipette. At 30 minutes postinfection, the wounds were subjected to different treatments.

A total of 20 rats were divided into four groups: group 1, control group, where the wounds were left untreated; group 2, plain-gel group, where a daily dose of $200 \mu \mathrm{L}$ of the gel were instilled into each wound; group 3, AgNP-gel group, where a daily dose of $200 \mu \mathrm{L}$ of the AgNP-loaded gel (equivalent to $18.3 \mu \mathrm{g}$ of AgNPs) was instilled into each wound; and group 4, AgNP-dispersion group, where a daily dose of $200 \mu \mathrm{L}$ of the dispersion (equivalent to $18.3 \mu \mathrm{g}$ of AgNPs) were instilled into each wound. After the respective treatment, the wounds were covered with transparent Tegaderm $^{\mathrm{TM}}$ (3M, St Paul, MN, USA) for the first 24 hours, to ensure the successful induction of infection. Rats were then returned to their cages and provided with unrestricted food and water supply. The rats remained under observation for 13 days. Wound healing was evaluated morphologically, microbiologically, and histologically. Wound diameter taken as the average of ten measurements in several directions at days $0,2,6,9,12$, and 13 was used to monitor the extent of wound contraction by calculating percentage wound closure. Daily swabs taken from each wound were cultured on appropriate media to detect the presence of wound infection. The fatalities in each group were also counted. At the end of the experiment, rats were killed using an overdose of an IP thiopental injection, and the tissues from the wound site, including the whole-skin thickness and surrounding skin, were removed for histological examination.

The specimens collected were fixed in $10 \%$ neutral formaldehyde. Wound sections were stained with hematoxylin and eosin and Masson's trichrome stain and examined microscopically.

\section{Statistical analysis}

Data obtained were subjected to statistical analysis using one way analysis of variance, followed by post hoc Duncan test. Analysis was done using SPSS 17 software (SPSS Inc, Chicago, IL, USA), where $P \leq 0.05$ denoted significance.

\section{Results and discussion Determination of the concentration of the prepared AgNPs}

The concentration of AgNPs was found to increase with increasing extract concentration, ie, increasing concentration of reducing agent (Table 1). This finding seemed to be consistent with Sathishkumar et al, ${ }^{22}$ who attributed increased AgNP concentration to the availability of more reducing biomolecules for the reduction of $\mathrm{Ag}^{+}$. The in vitro determination of free radical scavenging activity of various concentrations of Cr showed DPPH free radical scavenging activities of 0.135 , 0.238 , and $0.282 \mathrm{mg} \mathrm{AAe} / \mathrm{mL}$ extract for $\mathrm{Cr} 0.2 \%, \mathrm{Cr} 0.5 \%$, and $\mathrm{Cr} 0.8 \%$, respectively. The increased scavenging activity with increasing concentration of each extract indicated good reducing potential for the synthesis of AgNPs.

\section{$\xi$-Potential measurements}

The $\xi$-potential values of AgNP dispersions (Table 1) provided satisfactory evidence for the efficiency of the capping agents in stabilizing the NPs by providing intensive negative charges. This finding was in agreement with Dhas et al, ${ }^{23}$ who showed that the negative surface charge could be attributed to the adsorption of bioactive components present in the aqueous plant extract onto the surface of the NPs. Interestingly, a slight increase in $\xi$-potential values was observed with

Table I Concentration and $\zeta$-potential values of AgNPs prepared using cranberry powder aqueous extracts (Crs) of different concentrations

\begin{tabular}{lll}
\hline $\begin{array}{l}\text { AgNP } \\
\text { formulation }\end{array}$ & $\begin{array}{l}\text { Measured concentration } \\
(\mu \mathrm{g} / \mathbf{m L})\end{array}$ & $\begin{array}{l}\zeta \text {-Potential }^{\mathbf{a}} \\
(\mathbf{m V})\end{array}$ \\
\hline AgNPs $(\mathrm{Cr} 0.2 \%)$ & $9.13 \pm 0.095$ & $-31.3 \pm 0.05$ \\
AgNPs $(\mathrm{Cr} 0.5 \%)$ & $17.39 \pm 0.92$ & $-33.8 \pm 0.43$ \\
AgNPs (Cr 0.8\%) & $22.53 \pm 0.55$ & $-36.8 \pm 0.62$ \\
\hline
\end{tabular}

Note: ${ }^{a}$ Values listed are the average of three estimations \pm standard deviation. Abbreviation: AgNP, silver nanoparticle. 
increasing concentration of the extract, which could have been due to the greater availability of negatively charged capping agents.

\section{Morphological examination and particle- size measurement by TEM}

Figure 1 presents TEM images of the green-synthesized AgNPs, together with the corresponding histograms demonstrating the size distribution and PDIs. Particles were found to be approximately spherical in shape, with an average diameter of $1.4 \pm 0.8,2.8 \pm 2.1$, and $8.6 \pm 2.5 \mathrm{~nm}$ for AgNPs prepared using $\mathrm{Cr} 0.2 \%$, Cr $0.5 \%$, and $\mathrm{Cr} 0.8 \%$ extracts, respectively.

The increase in the plant-extract concentration in the reaction mixture resulted in an increase in both the concentration and the size of the prepared AgNPs. This could be ascribed to the increased amount of reducing agents in the reaction mixture with increasing extract concentration. The use of a
A

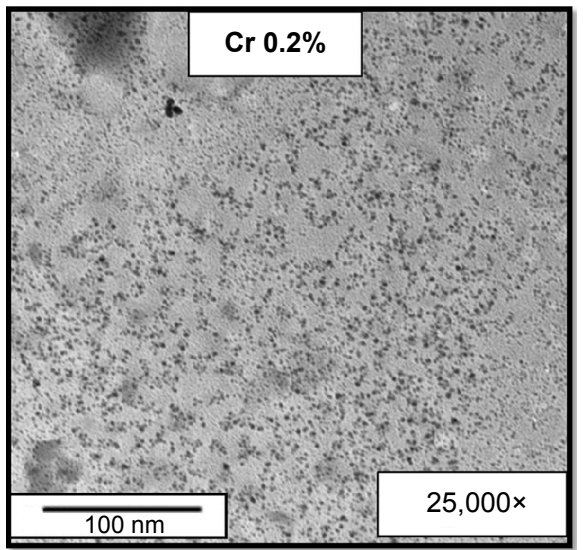

B

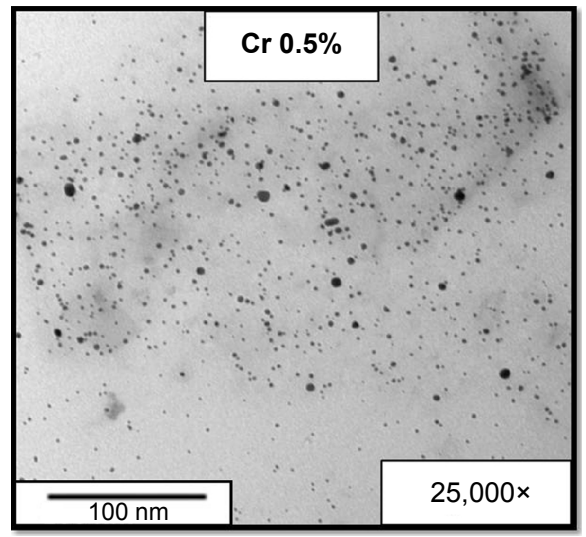

C

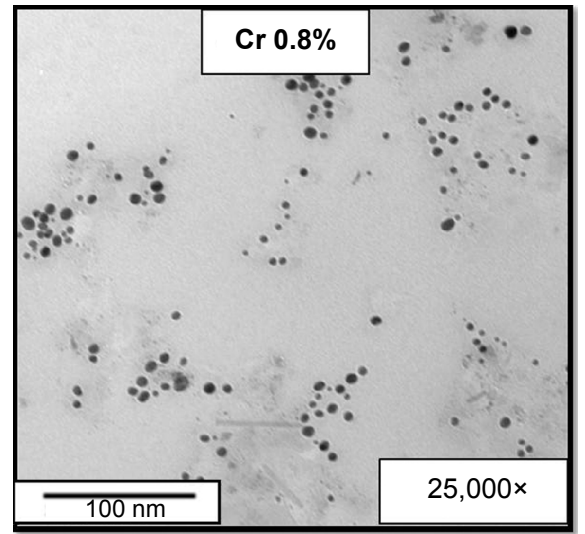

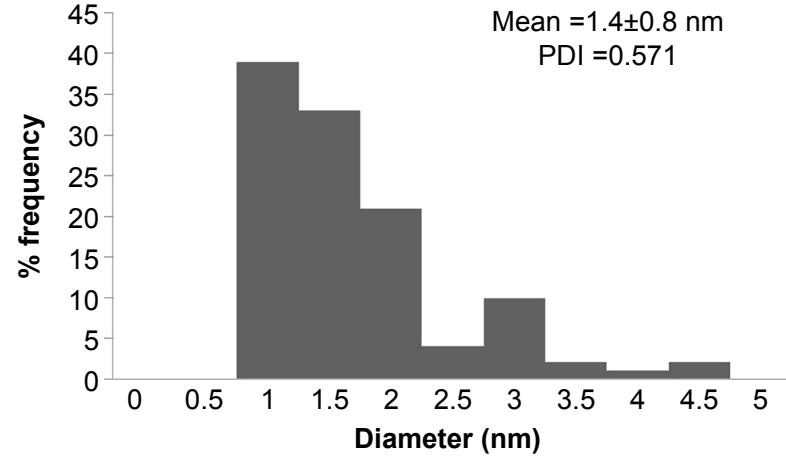
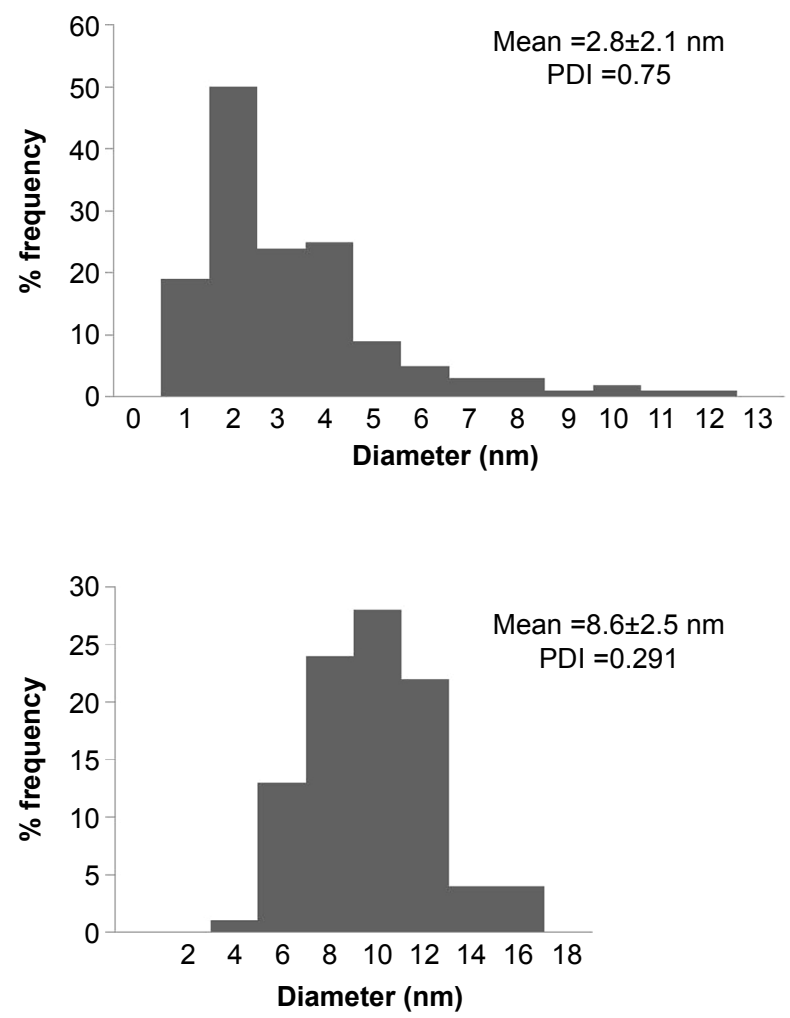

Figure I Transmission electron microscopy images and corresponding histograms showing particle-size distribution and PDIs of AgNPs prepared using cranberry powder aqueous extracts (Crs) of different concentrations: (A) $\mathrm{Cr}$ 0.2\%; (B) $\mathrm{Cr} 0.5 \%$; (C) $\mathrm{Cr} \mathrm{0.8 \%}$.

Abbreviations: AgNPs, silver nanoparticles; PDI, polydispersity index. 
higher extract concentration resulted in the production of more silver atoms, which nucleated to form smaller AgNPs that aggregated faster into more stable larger particles. ${ }^{24}$

Concerning the particle-size distribution, all the prepared AgNPs were polydisperse, as indicated by the PDI value. This could be attributed to variations in growth rates of individual particles in the nucleation step. ${ }^{17}$

\section{UV-vis absorbance spectroscopy}

Visual observation of the prepared AgNPs revealed a yellowish brown color (Figure 2), which was attributed to the characteristic surface-plasmon resonance absorption band of metal NPs. ${ }^{11,12}$ Also, Figure 2 illustrates that the color of the prepared AgNPs became darker as the extract concentration increased. Increasing the extract concentration above $0.8 \% \mathrm{w} / \mathrm{v}$ resulted in the formation of a grayish dispersion, indicating the formation of silver colloid due to particle aggregation, a finding previously reported by Mulfinger et al. ${ }^{25}$

The UV-vis spectra of the formed AgNPs for each extract showed an increase in peak intensity with increasing extract concentration (Figure 3), which could be attributed to the increased concentration of the formed NPs. This was in agreement with the results previously mentioned in Table 1, as well as those reported by Khalil et al. ${ }^{12}$ The slight red shift in the maximum absorption value of the prepared NPs with increasing concentration (Figure 3) could be explained by a slight increase in the particle size of the formed NPs. ${ }^{26}$ Moreover, the polydispersity of the prepared NPs, as previously revealed by the TEM examination, is believed to be mirrored in the broad spectral surface-plasmon resonance peaks of all NPs (Figure 3). ${ }^{27}$

\section{Fourier-transform infrared spectroscopy}

The dual role of the plant extract as a bioreductant and capping agent was confirmed by FT-IR analysis of the prepared

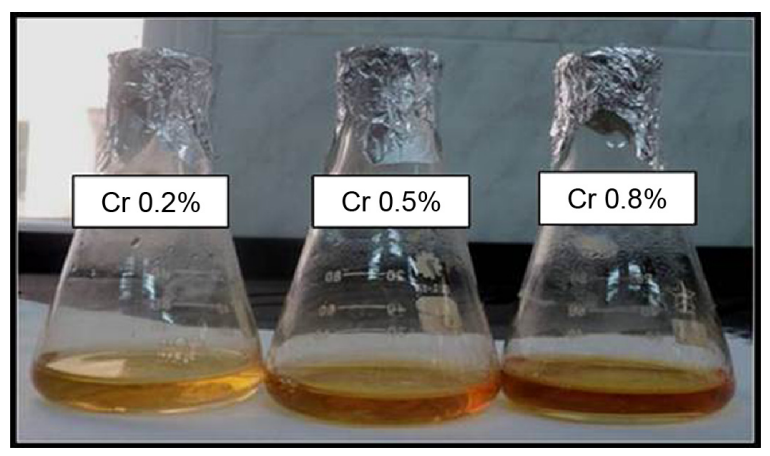

Figure 2 Silver nanoparticles prepared using different concentrations $(0.2 \%, 0.5 \%$, and $0.8 \% \mathrm{w} / \mathrm{v}$ ) of cranberry powder aqueous extracts (Crs).

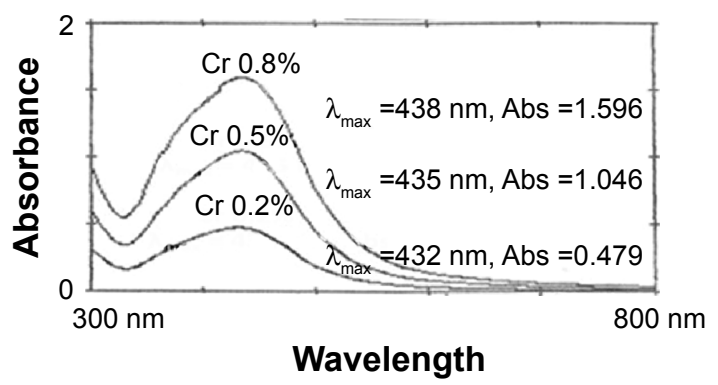

Figure 3 Ultraviolet-visible spectra of silver nanoparticles prepared using different concentrations of cranberry powder aqueous extracts (Crs).

Abbreviation: Abs, absorbance.

AgNPs (Figure 4). The similarities between the spectra of AgNPs prepared using $\mathrm{Cr} 0.8 \%$ and the corresponding extract depicted in the aforementioned figure, with some marginal shifts in peak position, clearly indicated the presence of residual plant-extract components on the surface of AgNPs as capping agents. ${ }^{28}$

The absorption bands around 3,760 and 3,400 $\mathrm{cm}^{-1}$ in the extract's spectrum could result from bonded hydroxyl $(-\mathrm{OH})$ groups of phenols and carboxylic acids. ${ }^{28}$ The band at $2,925 \mathrm{~cm}^{-1}$ could be attributed to the stretching vibration of $\mathrm{C}-\mathrm{H}$ groups of aliphatic acids. ${ }^{29}$ However, this band split into two bands in the AgNP spectrum (at 2,917 and 2,851 $\mathrm{cm}^{-1}$ ), indicating the stretching vibration of methylene groups $\left(-\mathrm{CH}_{2}\right)$ in aliphatic hydrocarbons. The new band observed in the AgNP spectrum at $1,720 \mathrm{~cm}^{-1}$ may indicate the presence of a new $\mathrm{C}=\mathrm{O}$ group belonging to either a ketone or an aldehyde. This strongly suggested that the reduction of $\mathrm{Ag}^{+}$ was carried out by some hydroxyl groups that were oxidized into carbonyl groups. ${ }^{28}$

It could therefore be concluded that AgNPs had a strong binding ability to many functional groups of the various constituents of the plant material, such as polyphenolics and proteins, suggesting the formation of a layer covering AgNPs and acting as capping agent, thus preventing agglomeration and providing stability to the NPs.

\section{Evaluation of the in vitro antimicrobial activity of AgNPs}

MIC estimation is a classical method for assessing the potency of an antimicrobial agent. The MIC and MLC values of various AgNP formulations against a number of test microorganisms are listed in Table 2.

The MIC values of the different AgNP formulations against the various test microorganisms ranged between 9.9 and $79 \mu \mathrm{g} / \mathrm{mL}$, while MLC values were slightly higher $(12.7-81.7 \mu \mathrm{g} / \mathrm{mL})$. These relatively low values indicated 


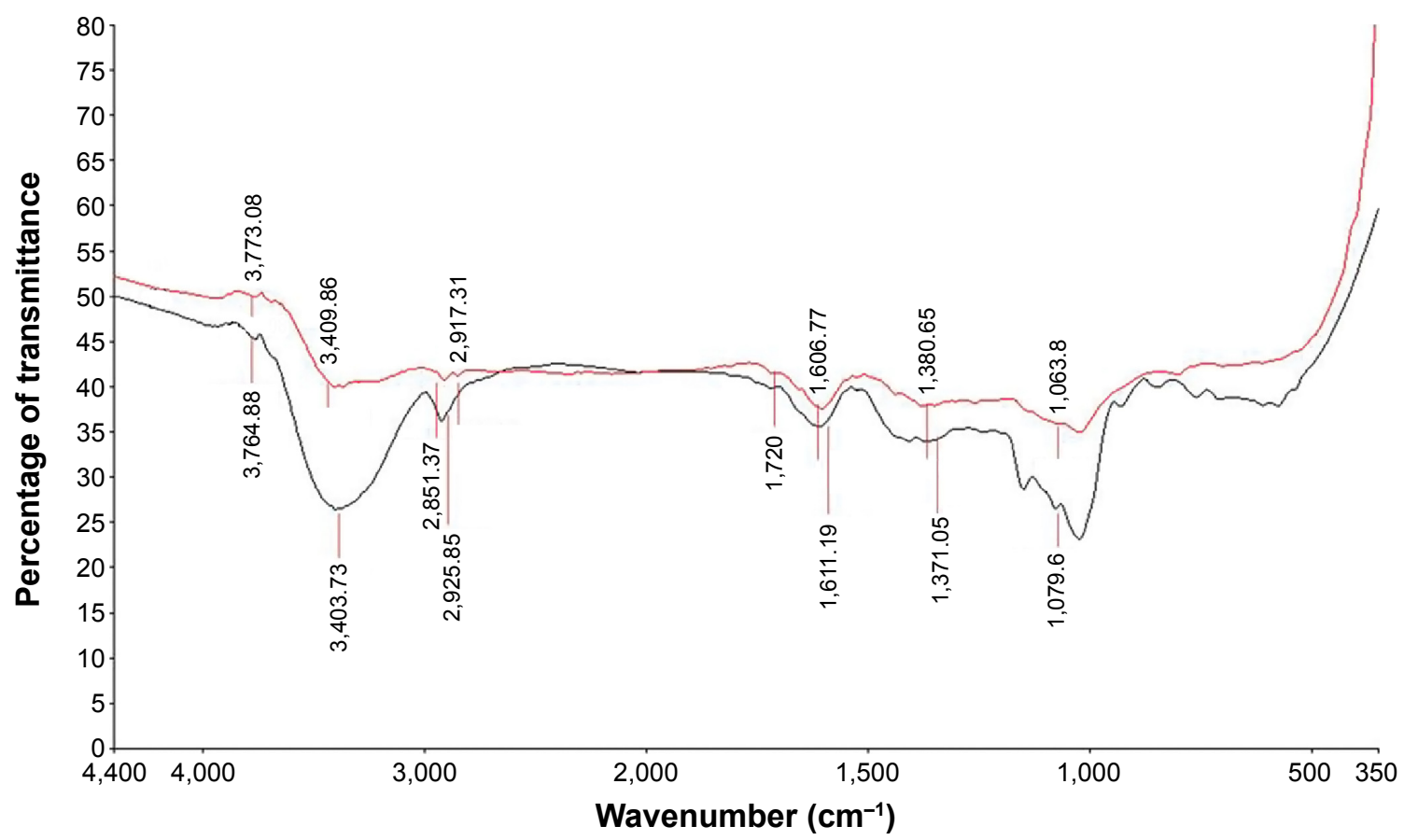

Figure 4 Fourier-transform infrared spectra.

Notes: Purified green-synthesized silver nanoparticles obtained after bioreduction (red line) and cranberry dry-powder extract (black line).

good bacteriostatic and fungicidal activity. In general, the antibacterial activity of the AgNPs was more pronounced than their antifungal activity, as indicated by the lower MIC values (Table 2). Similar results were reported by Nabikhan et a ${ }^{30}$ and Puišo et al. ${ }^{18}$ In the latter study, this was attributed to the adsorption of silver onto the bacterial surface, thereby inhibiting bacterial respiration, which occurs across the cell membrane, rather than across the mitochondrial membrane of the eukaryotic fungi. However, our finding was in contrast to an earlier investigation by Kim et al, ${ }^{31}$ who found yeast to be more susceptible to the effect of AgNPs than S. aureus, and to other studies that have reported comparable antifungal and antibacterial effects for AgNPs. ${ }^{32,33}$

Furthermore, it should be noted that the $\mathrm{Cr} 0.8 \%$ formulation showed a higher effect against Gram-negative bacteria compared to Gram-positive ones. This observation is consistent with the findings of other published studies, and can be attributed to differences in their respective cell-wall structure. Compared to Gram-negative bacteria, the cell wall of Gram-positive bacteria is thicker and thus probably more difficult for AgNPs to penetrate..$^{31,34-36}$

Moreover, it is worth mentioning that for all of the tested AgNP formulations, the MIC values for the drug-resistant (methicillin-resistant S. aureus) and susceptible (standardstrain $S$. aureus) strains were almost identical, indicating that the activity of the prepared AgNPs is unaffected by resistance mechanisms that differentiate both strains. This is in agreement with previous studies, where AgNPs were found to exert the same effects on drug-resistant and drugsusceptible bacteria. ${ }^{37,38}$

One unanticipated finding was that the effect on the multidrug-resistant $P$. aeruginosa isolate was greater than

Table 2 MIC and MLC values of the different AgNP formulations for various organisms

\begin{tabular}{|c|c|c|c|c|c|}
\hline \multirow[t]{2}{*}{ AgNP formulation } & \multicolumn{5}{|c|}{ MIC/MLC ${ }^{a}(\mu g / m L)$} \\
\hline & $\begin{array}{l}\text { S. aureus } \\
\text { ATCC } 6538 \mathrm{P}\end{array}$ & MRSA & $\begin{array}{l}\text { P. aeruginosa } \\
\text { ATCC } 9027\end{array}$ & $\begin{array}{l}\text { MDR } \\
\text { P. aeruginosa }\end{array}$ & $\begin{array}{l}\text { C. albicans } \\
\text { ATCC 2091 }\end{array}$ \\
\hline AgNPs (Cr 0.2\%) & $18.3 / 36.6$ & $18.3 / 36.6$ & $19.8 / 29.3$ & $9.9 / 19.8$ & $38.3 / 38.3$ \\
\hline AgNPs (Cr 0.5\%) & $20.4 / 40.9$ & $20.4 / 81.7$ & $20.4 / 27.2$ & $12.7 / 12.7$ & $61.3 / 61.3$ \\
\hline AgNPs (Cr 0.8\%) & $39.5 / 79$ & $39.5 / 79$ & $25.3 / 28.2$ & $12.7 / 19.8$ & 79/79 \\
\hline
\end{tabular}

Note: ${ }^{\mathrm{V}}$ alues listed represent the average of three determinations.

Abbreviations: MIC, minimum inhibitory concentration; MLC, minimum lethal concentration; AgNP, silver nanoparticle; S. aureus, Staphylococcus aureus; MRSA, methicillinresistant S. aureus; P. aeruginosa, Pseudomonas aeruginosa; MDR, multidrug-resistant; $C$. albicans, Candida albicans; Cr, cranberry powder aqueous extract. 
that on its susceptible counterpart, contrary to what was reported by Amirulhusni et al, ${ }^{39}$ where both drug-susceptible and -resistant strains of $P$. aeruginosa were similarly affected. This might be attributable to differences in the experimental setting, including the size and concentration of AgNPs, the strains tested, and the nature of the antimicrobial assay.

Interestingly, the antimicrobial activity of the AgNP formulations was highly dependent upon their particle size. The MIC values for the different organisms increased as the particle size of the AgNPs increased from 1.4 to $8.6 \mathrm{~nm}$ (AgNPs prepared using $\mathrm{Cr} 0.2 \%$ and $\mathrm{Cr} 0.8 \%$, respectively) (Table 2). The enhanced activity of AgNPs with decreasing particle size corroborates earlier findings by $\mathrm{Lu}$ et $\mathrm{al}^{4}$ and Durán et al. ${ }^{40}$ A possible explanation for this might be that the decreasing particle size of AgNPs results in an increase in their surface area in contact with bacteria and consequently in enhanced penetration. ${ }^{4}$

\section{Study of bacteria-killing kinetics}

The kinetics of the time-dependent killing of bacterial populations in MHB were monitored at regular 1-hour intervals (up to 24 hours) using viable count estimations of bacterial suspensions treated with AgNPs ( $\mathrm{Cr} 0.2 \%$ ) compared to an appropriate control (Figure 5). This AgNP formulation was chosen based on its high antimicrobial efficacy (Table 2), as well as the fact that it was prepared using a low extract concentration, which is important from an economic point of view.

Based on the data depicted in Figure 5, P. aeruginosa (a Gram-negative bacterium) was killed faster than its Grampositive counterpart (S. aureus), the former being more sensitive to lower concentrations of AgNPs, an observation that coincides with Jain et al. ${ }^{41}$ More precisely, AgNPs achieved a $3 \log _{10}$ decrease in the viable count of $P$. aeruginosa ATCC

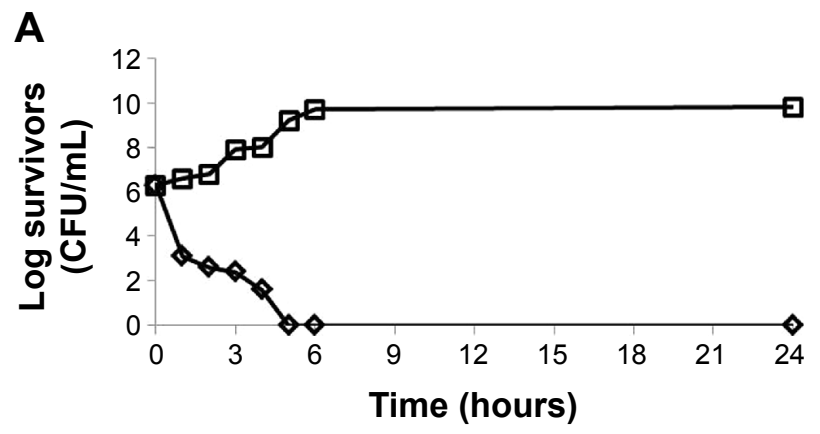

9027 in the 1 st hour, followed by complete eradication within 5 hours, whereas the control showed a steady growth throughout the study period. As for $S$. aureus ATCC 6538P, a $1 \log _{10}$ decrease in viability occurred within 5 hours of exposure to AgNPs; the effect extended over 6 hours, and was then followed by a $4 \log _{10}$ decrease in survivor count up to 24 hours. This apparent discrepancy in the effect of AgNPs on both Gram-negative and Gram-positive bacteria would be attributed to differences in their respective cell-wall structures, as mentioned earlier.

\section{Estimation of the effect of AgNPs on bacterial cell structure using SEM}

SEM was used to monitor ultrastructural changes in bacterial morphology and to identify potential damages upon exposure to the prepared AgNPs ( $\mathrm{Cr} 0.2 \%$ ). Control cells showed an intact and more or less uniform surface (Figure 6, left pane). On the other hand, treatment of exponentially growing bacteria with AgNPs for 3.5 hours ( $P$. aeruginosa ATCC 9027) and 8 hours (S. aureus ATCC 6538P) caused major damage to the treated cells, seen as a disrupted and frayed cell envelope, with possible release of cellular contents (Figure 6). The obtained results seemed to be consistent with the morphological changes observed by Marius et al, ${ }^{42}$ who attributed their findings to clusters of AgNPs attaching onto the bacterial cell surface, probably inducing the formation of distinct perforations in the cell membrane, and ultimately resulting in cell lysis.

\section{In vivo antimicrobial and wound- healing effect of AgNP-Pluronic F-I 27 thermosensitive gel in rats}

Green-synthesized AgNP-Pluronic F-127 thermosensitive gel was prepared and used to treat localized infected

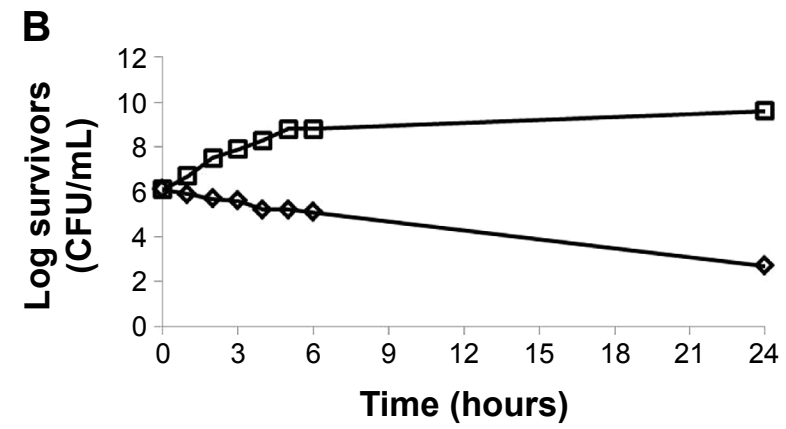

Figure 5 Killing curve of AgNPs prepared using 0.2\% cranberry powder aqueous extract (Cr 0.2\%) against (A) Pseudomonas aeruginosa ATCC 9027 ; (B) Staphylococcus aureus ATCC 6538P.

Abbreviation: AgNPs, silver nanoparticles. 
A

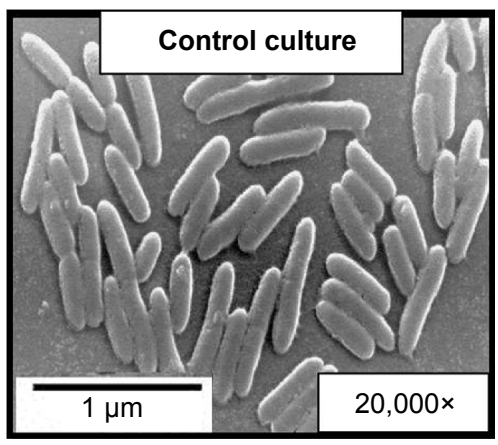

C

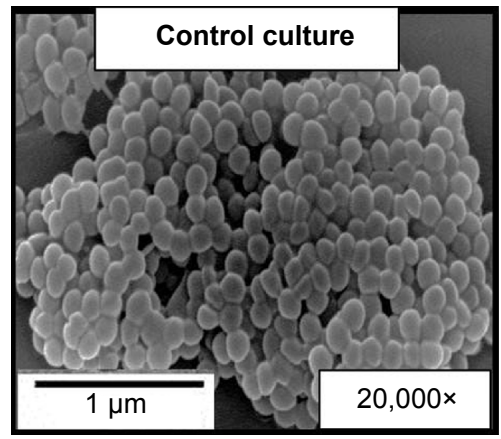

B

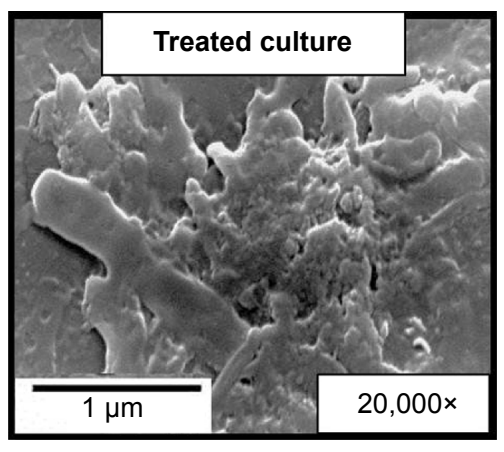

D

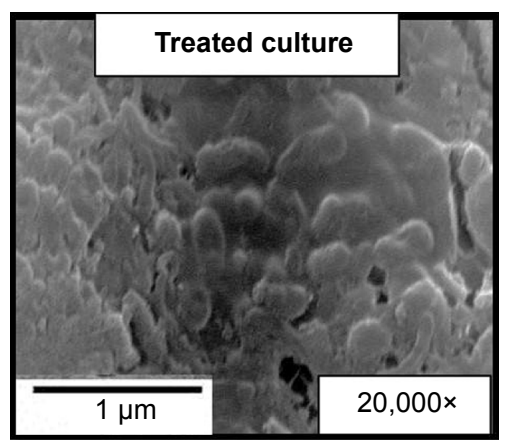

Figure 6 Scanning electron microscopy images.

Notes: Cultures of Pseudomonas aeruginosa ATCC 9027 (A and B) and Staphylococcus aureus ATCC 6538P (C and D). The left pane (A and C) depicts control cultures, while the right pane (B and $\mathbf{D})$ involves cultures treated with $\mathrm{AgNPs}(\mathrm{Cr} 0.2 \%)$ for 3.5 (B) and 8 (D) hours, respectively.

Abbreviations: AgNPs, silver nanoparticles; $\mathrm{Cr}$, cranberry powder aqueous extract.

excision wounds. The AgNP preparation (Cr $0.2 \%)$ was chosen, since it displayed a high antibacterial activity against S. aureus, a pathogen commonly found in infected wounds, and because NPs were prepared using a low extract concentration. Reduction of microbial load, histopathological examination, and healing of S. aureus-infected excision wounds in male albino rats were used as monitoring parameters.

Figure 7 shows digital photographs depicting the healing progress of excision $S$. aureus-infected wounds in rats. Figure 8, illustrating the mean percentage wound-closure data based on wound-size measurements during the study period, shows that untreated wounds did not close completely until the end of the experiment (13 days), indicating persistent wound infection (a fact corroborated by microbiological monitoring). In comparison to the untreated control group, the plain gel-treated animals showed a slight improvement at day 13. However, their mean percentage wound closure at that day did not differ significantly $(P>0.05)$ from that of the control (untreated) group. On the other hand, faster and more efficient healing was observed for the two AgNPbased preparations, with statistically significant $(P \leq 0.05)$ mean percentage wound closure at day 13 when compared to control wounds.

The greatest wound closure was achieved at day 13 using the AgNP dispersion (95.4\%), followed by the AgNP gel (91.4\%); however, this difference was not statistically significant $(P>0.05)$ indicating that the wound-healing properties of the AgNPs were not significantly affected by the gel matrix. Conversely, the untreated and plain geltreated groups showed maximum wound closure of $84.6 \%$ and $88.4 \%$, respectively, at day 13 .

Although statistical analysis of the results revealed that percentage wound closure of the plain gel-treated group was significantly higher compared to the untreated one at days 2 and $6(P \leq 0.05)$, the difference was insignificant $(P>0.05)$ on subsequent days $(9,12$, and 13$)$. The slight improvement in the early healing process (days 2 and 6 ) of the plain-gel group could be ascribed to the wound-healing properties of Pluronic F-127 gel, possibly by stimulation of epithelial growth factors. ${ }^{43}$ The results of the current study seemed to be consistent with those published previously. ${ }^{44,45}$ For instance, Thirumurugan et $\mathrm{al}^{44}$ synthesized AgNPs from potato plant pathogenic fungus. The results of woundhealing activity of the AgNP $0.125 \%(\mathrm{w} / \mathrm{w})$ ointments revealed significant wound-healing properties compared to standard silver sulfadiazine ointment currently available in the market. Similarly, Prestes et $a l^{45}$ found that nanocrystalline silver dressing exhibited good wound-healing potential in relation to wound contraction compared to the control group.

According to Table 3, which lists the percentage of infected wounds and number of fatalities throughout the first 

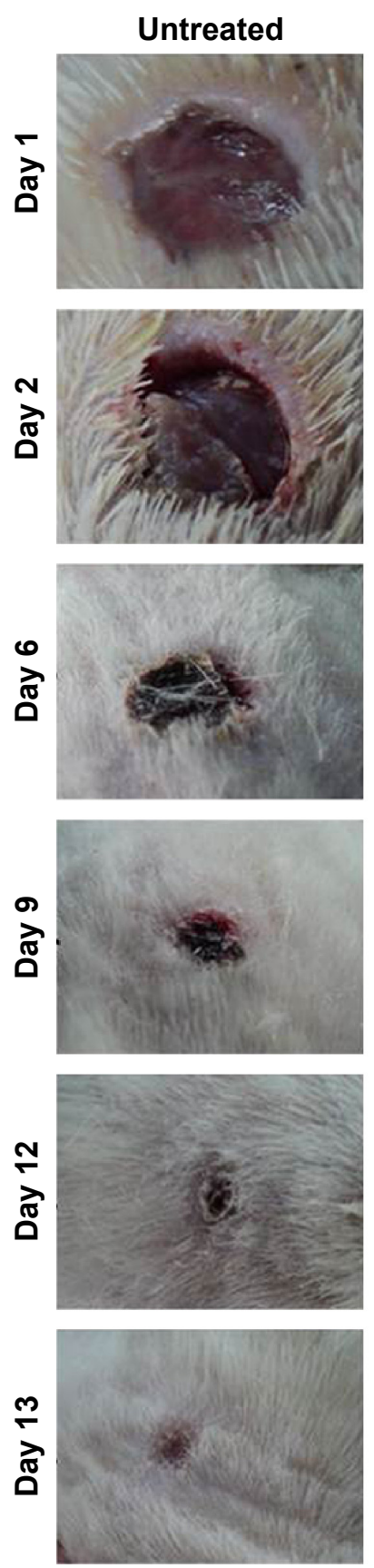
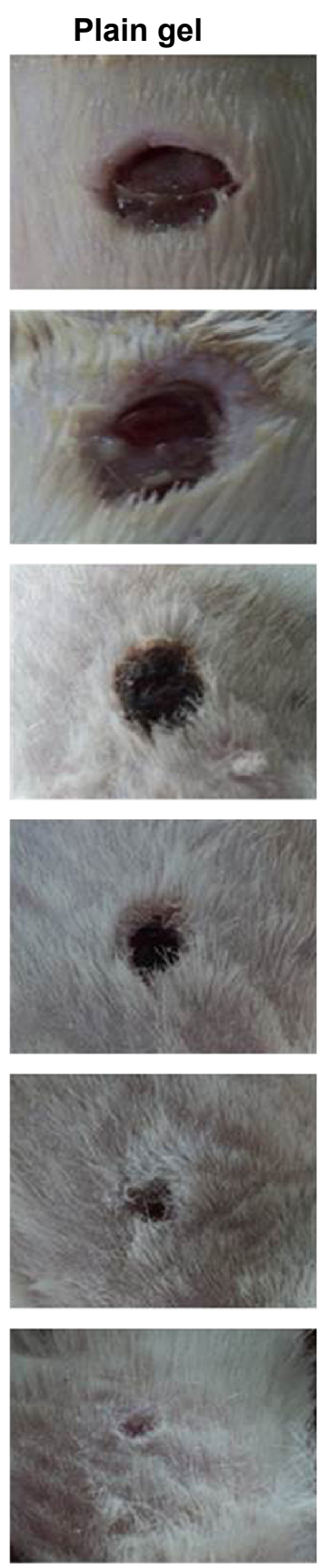

\section{AgNP dispersion}
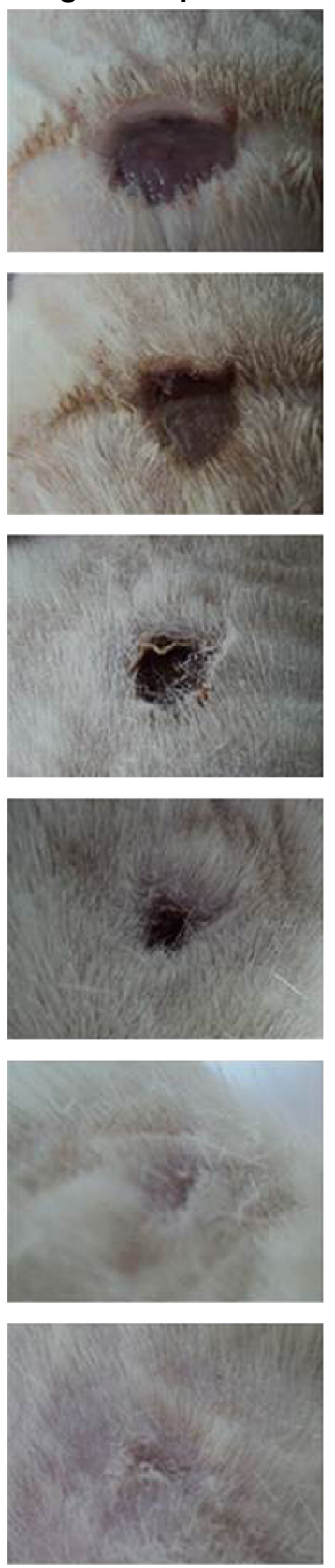

\section{AgNP gel}
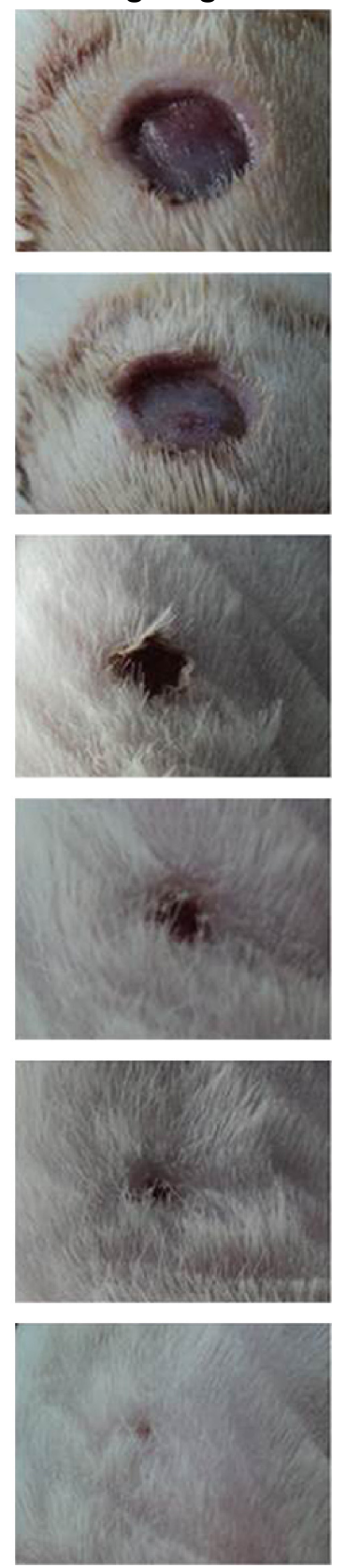

Figure 7 Digital photographs showing the healing progress of excision Staphylococcus aureus-infected wounds in rats. Abbreviation: $\mathrm{AgNP}$, silver nanoparticle.

8 days of the study period, only one fatality was recorded in untreated rats, whereas no fatalities were observed with other treatments. The percentage of wound infection remained at $100 \%$ for all tested groups up to day 3, except for those treated with AgNP gel, where it decreased to $90 \%$. At day 8, the infection subsided to $75 \%$ and $70 \%$ for untreated and plain gel-treated rats, respectively, probably due to the rats' host-defense mechanisms. ${ }^{46}$ On that same day, however, wounds of rats treated with AgNP-based preparations were microbe-free, confirming effective antimicrobial control.
It is worth mentioning that the AgNP gel showed a more prominent reduction in percentage infection compared to the AgNP dispersion up to day 6, which might be attributed to the longer retention time of the gel compared to the aqueous dispersion. Moreover, this constituted sufficient proof that the antimicrobial activity of the AgNPs was not affected by the gel matrix.

Results of histological examination using hematoxylin and eosin and Masson's trichrome staining for normal as well as wounded skin are shown in Figures 9 and 10, respectively. 


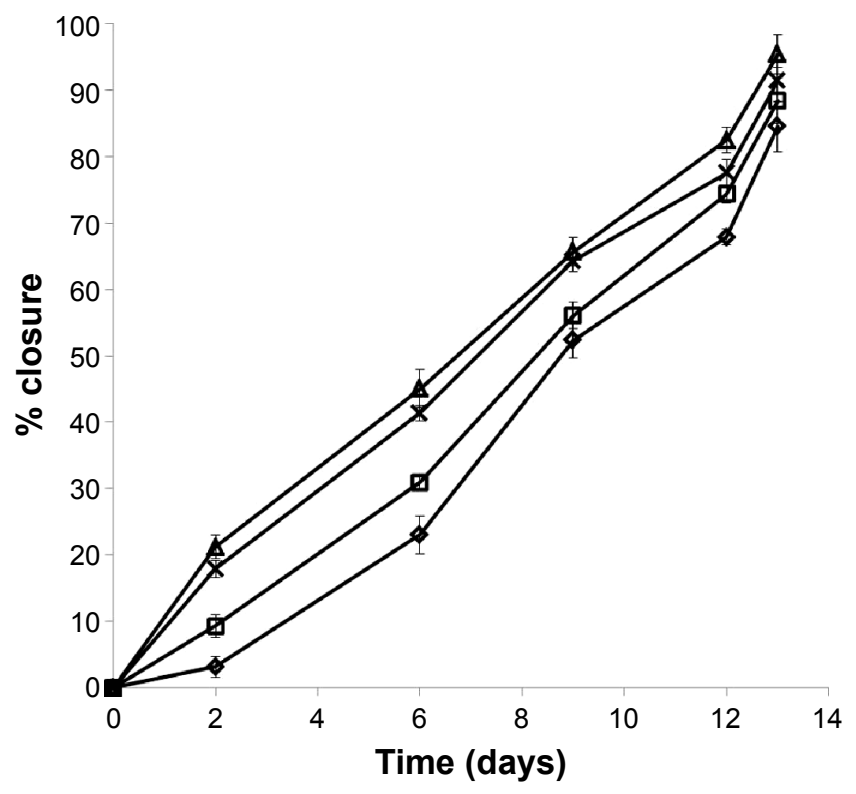

— Untreated
— Gel
$\star$ AgNP dispersion
$\star$ AgNP gel

Figure 8 Percentage mean wound closure over a period of I 3 days, measured morphometrically.

Note: $\mathrm{n}=10$ in all groups, except for the untreated group, where $\mathrm{n}=8$.

Abbreviation: AgNP, silver nanoparticle.

Table 3 Percentage of infected excision wounds and number of fatalities in rats treated with AgNP gel in comparison to rats treated with AgNP dispersion, rats treated with plain gel, and untreated rats, during 8 days of the study period

\begin{tabular}{|c|c|c|c|c|c|c|c|c|}
\hline \multirow[t]{2}{*}{ Rat group } & \multicolumn{7}{|c|}{ Percentage infected wounds on study days } & \multirow[t]{2}{*}{ Fatalities } \\
\hline & $\mathbf{I}$ & 2 & 3 & 5 & 6 & 7 & 8 & \\
\hline Untreated & 100 & 100 & 100 & 100 & 100 & 100 & 75 & 1 \\
\hline Plain gel & 100 & 100 & 100 & 100 & 90 & 70 & 70 & 0 \\
\hline AgNP dispersion & 100 & 100 & 100 & 90 & 60 & 20 & 0 & 0 \\
\hline AgNP gel & 100 & 100 & 90 & 70 & 50 & 20 & 0 & 0 \\
\hline
\end{tabular}

Abbreviation: AgNP, silver nanoparticle.
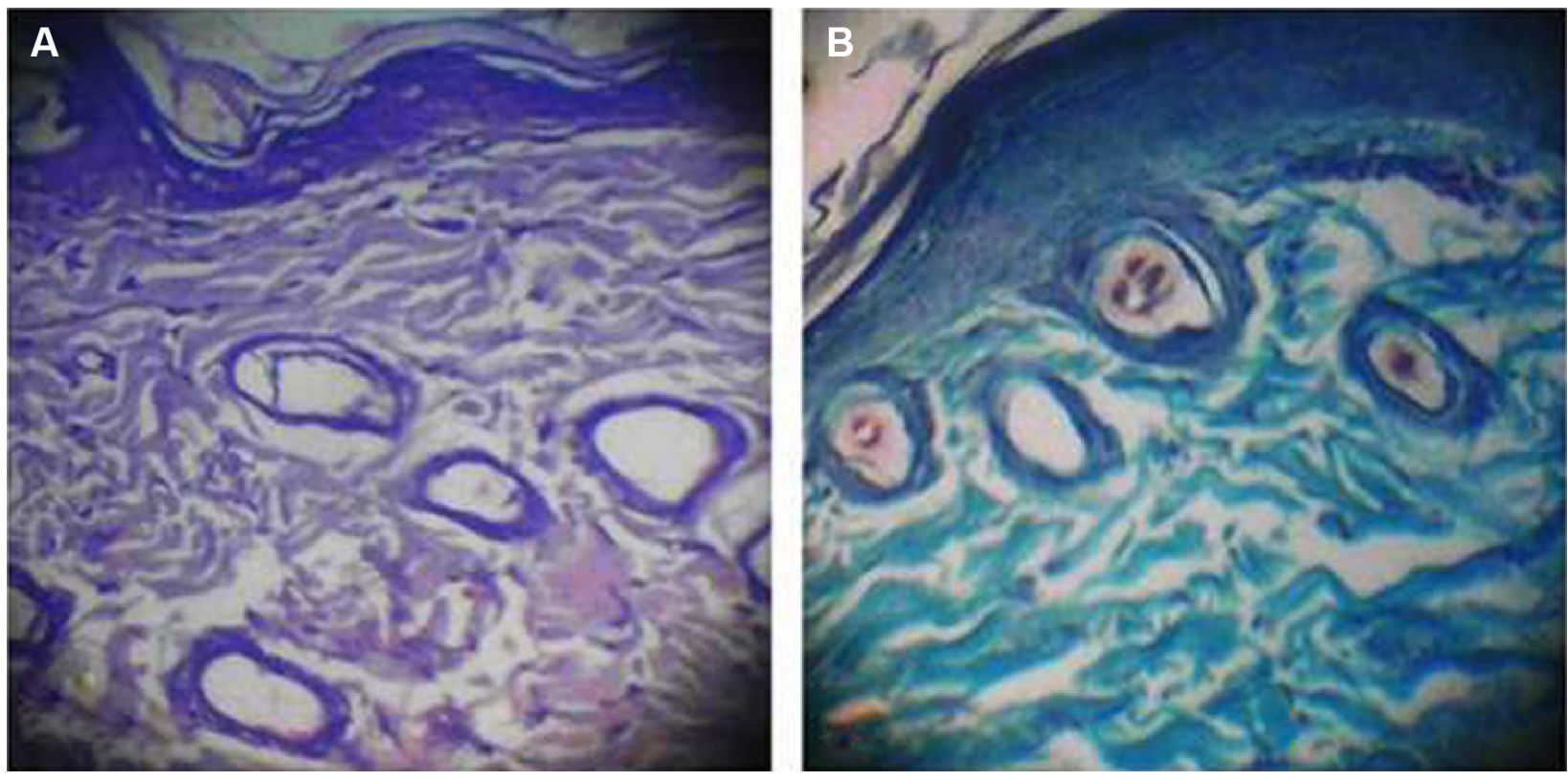

Figure 9 Histological examination at a magnification power of $100 \times$ of a section in normal rat skin. Notes: Stained with hematoxylin and eosin (A) and Masson's trichrome (B). 

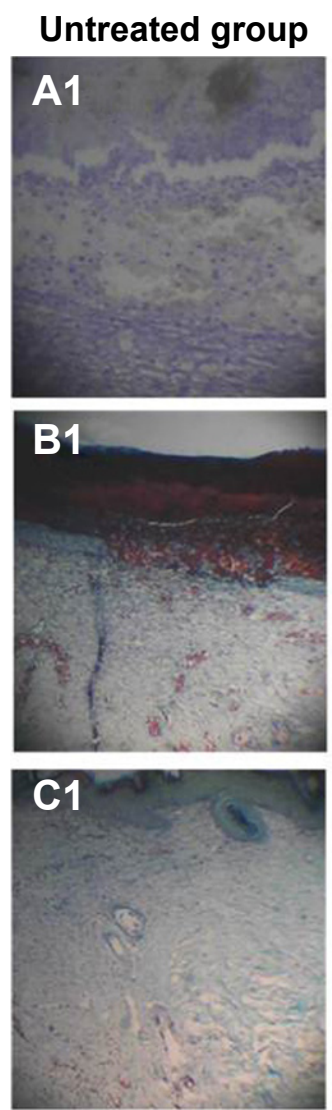
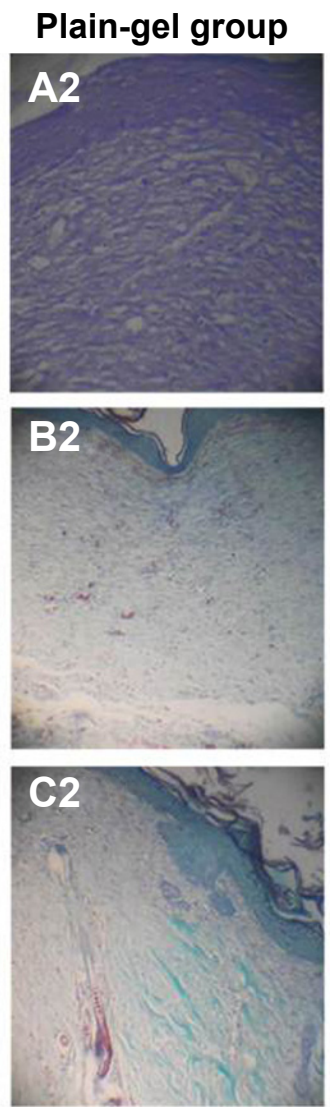

\section{AgNP group}
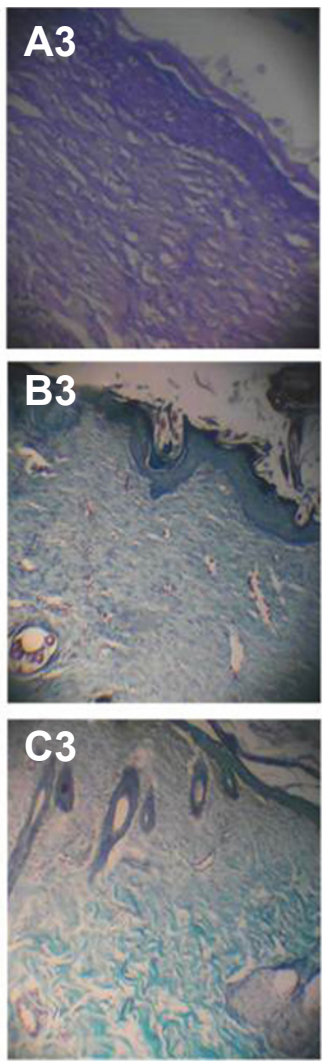

\section{AgNP gel group}
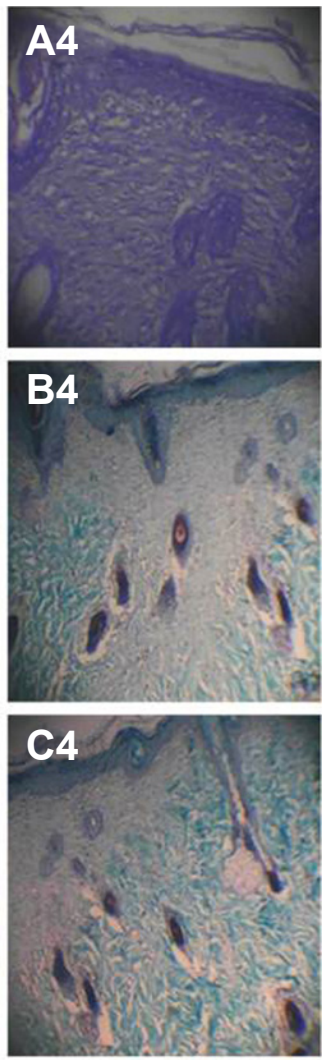

Figure 10 Histological examination of excision wounds in rat skin of different animal groups.

Notes: (AI-A4) Wound bed stained with hematoxylin and eosin (magnification I00×). Wound bed (BI-B4) and edge (CI-C4) stained with Masson's trichrome (magnification 40X).

Abbreviation: AgNP, silver nanoparticle.

Compared to normal skin, the untreated wound sections showed an incomplete epithelium at the wound center and extensive loose granulation tissue that lacked the presence of well-defined collagen fibers in the wound bed (Figure 10, $\mathrm{A} 1$ and B1). At the wound margins, the ill-defined collagen fibers from untreated wounds had the least staining intensity (Figure 10, C1).

On the other hand, plain gel-treated wounds showed an enhanced integrity of the granulation tissue, with a fully developed epithelium at the wound center (Figure 10, A2 and B2) and an enhanced deposition of collagen fibers at the wound margins (Figure 10, C2) compared to the untreated group. However, there were still few areas of loose extracellular matrix at the wound center, with a reduced presence of collagen fibers, which was still higher than that seen in untreated groups. In addition, there was no sprouting of hair follicles in the wound area in the plain gel-treated group.

Sections taken from wounds treated with AgNPs (whether aqueous dispersion or gel) for 13 days showed enhanced integrity of the granulation tissue and a fully developed epithelium. Both treatments were equipotent with regard to improving the deposition of collagen fibers at the wound bed and wound margin, which was significantly higher than that observed for both the untreated and plain gel-treated groups. Although both AgNP treatments showed remarkable remodeling of the collagen fibers at the wound margins (Figure 10, C3 and C4), the granulation tissue was not fully resolved at the wound center (Figure 10, B3 and B4). Nevertheless, the significant staining intensity of the collagen fibers and their near-normal size, shape, and orientation at the wound edges indicated good healing potential for both the AgNP dispersion and the gel. Interestingly, both AgNP preparations showed sprouting of hair follicles at both the wound margin and center, indicating minimal scarring during wound healing. ${ }^{47}$

\section{Conclusion}

The green synthesis of AgNPs was successfully achieved using various concentrations of cranberry fruit dried extract powder. These extracts were proven to act as both reducing as well as capping agents for the prepared particles. Interestingly, both size and concentration of the prepared 
particles increased upon increasing the extract concentration. Moreover, the prepared AgNPs possessed good, sizedependent in vitro antimicrobial activity against a number of Gram-positive and Gram-negative bacteria, as well as yeast, with significantly higher antibacterial activity. Remarkably, Gram-negative bacteria were more susceptible to the effect of AgNPs than Gram-positive ones. Finally, the prepared NPs, either in aqueous dispersion or as a Pluronic F-127 thermosensitive gel, exhibited potent in vivo antimicrobial as well as wound-healing potential in rats.

\section{Disclosure}

The authors report no conflicts of interest in this work.

\section{References}

1. Huh AJ, Kwon YJ. "Nanoantibiotics": a new paradigm for treating infectious diseases using nanomaterials in the antibiotics resistant era. J Control Release. 2011;156(2):128-145.

2. Pal S, Tak YK, Song JM. Does the antibacterial activity of silver nanoparticles depend on the shape of the nanoparticle? A study of the Gram-negative bacterium Escherichia coli. Appl Environ Microbiol. 2007;73(6):1712-1720.

3. Prabhu S, Poulose EK. Silver nanoparticles: mechanism of antimicrobial action, synthesis, medical applications, and toxicity effects. Int Nano Lett. 2012;2(1):1-10.

4. Lu Z, Rong K, Li J, Yang H, Chen R. Size-dependent antibacterial activities of silver nanoparticles against oral anaerobic pathogenic bacteria. J Mater Sci Mater Med. 2013;24(6):1465-1471.

5. Furno F, Morley KS, Wong B, et al. Silver nanoparticles and polymeric medical devices: a new approach to prevention of infection? J Antimicrob Chemother. 2004;54(6):1019-1024.

6. Li Y, Leung P, Yao L, Song Q, Newton E. Antimicrobial effect of surgical masks coated with nanoparticles. J Hosp Infect. 2006;62(1):58-63.

7. Mecha CA, Pillay VL. Development and evaluation of woven fabric microfiltration membranes impregnated with silver nanoparticles for potable water treatment. J Memb Sci. 2014;458:149-156.

8. Atta AM, El-Mahdy GA, Al-Lohedan HA, Ezzat AO. Preparation of crosslinked amphiphilic silver nanogel as thin film corrosion protective layer for steel. Molecules. 2014;19(7):10410-10426.

9. Das VL, Thomas R, Varghese RT, Soniya EV, Mathew J, Radhakrishnan EK. Extracellular synthesis of silver nanoparticles by the Bacillus strain CS 11 isolated from industrialized area. Biotech. 2014;4(2): 121-126.

10. Syed A, Saraswati S, Kundu GC, Ahmad A. Biological synthesis of silver nanoparticles using the fungus Humicola sp. and evaluation of their cytoxicity using normal and cancer cell lines. Spectrochim Acta A Mol Biomol Spectrosc. 2013;114:144-147.

11. Jagtap UB, Bapat VA. Green synthesis of silver nanoparticles using Artocarpus heterophyllus Lam. seed extract and its antibacterial activity. Ind Crops Prod. 2013;46:132-137.

12. Khalil MM, Ismail EH, El-Baghdady KZ, Mohamed D. Green synthesis of silver nanoparticles using olive leaf extract and its antibacterial activity. Arab J Chem. 2014;7(6):1131-1139.

13. Ghosh S, Patil S, Ahire M, et al. Synthesis of silver nanoparticles using Dioscorea bulbifera tuber extract and evaluation of its synergistic potential in combination with antimicrobial agents. Int J Nanomedicine. 2012;7:483-496.

14. Satyavani K, Ramanathan T, Gurudeeban S. Green synthesis of silver nanoparticles by using stem derived callus extract of bitter apple (Citrullus colocynthis). Dig J Nanomater Biostruct. 2011;6(3): 1019-1024.
15. Mittal AK, Chisti Y, Banerjee UC. Synthesis of metallic nanoparticles using plant extracts. Biotech Adv. 2013;31(2):346-356.

16. Neto CC. Cranberry and its phytochemicals: a review of in vitro anticancer studies. J Nutr. 2007;137(1):186S-193S.

17. Singh R, Magesh S, Rakkiyappan C. Formation of fenugreek (Trigonella foenum-graecum) extract mediated Ag nanoparticles: mechanism and applications. Int J Bioeng Sci Technol. 2011;2(3):64-73.

18. Puišo J, Jonkuvienė D, Mačionienė I, Šalomskienė J, Jasutienė I, Kondrotas R. Biosynthesis of silver nanoparticles using lingonberry and cranberry juices and their antimicrobial activity. Colloids Surf $B$ Biointerfaces. 2014;121:214-221.

19. Mărghitaş LA, Stanciu OG, Dezmirean DS, et al. In vitro antioxidant capacity of honeybee-collected pollen of selected floral origin harvested from Romania. Food Chem. 2009;115(3):878-883.

20. Salem HF, Eid KA, Sharaf MA. Formulation and evaluation of silver nanoparticles as antibacterial and antifungal agents with a minimal cytotoxic effect. Int J Drug Deliv. 2011;3(2):293-304.

21. Andrews JM. Determination of minimum inhibitory concentrations. J Antimicrob Chemother. 2001;48 Suppl 1:5-16.

22. Sathishkumar M, Sneha K, Won SW, Cho CW, Kim S, Yun YS. Cinnamon zeylanicum bark extract and powder mediated green synthesis of nano-crystalline silver particles and its bactericidal activity. Colloids Surf B Biointerfaces. 2009;73(2):332-338.

23. Dhas SP, Mukerjhee A, Chandrasekaran N. Phytosynthesis of silver nanoparticles using Ceriops tagal and its antimicrobial potential against human pathogens. Int J Pharm Pharm Sci. 2013;5(3):349-352.

24. Kumar V, Yadav SK. Synthesis of different-sized silver nanoparticles by simply varying reaction conditions with leaf extracts of Bauhinia variegata L. IET Nanobiotechnol. 2012;6(1):1-8.

25. Mulfinger L, Solomon SD, Bahadory M, Jeyarajasingam AV, Rutkowsky SA, Boritz C. Synthesis and study of silver nanoparticles. J Chem Educ. 2007;84(2):322-325.

26. Xia Y, Halas NJ. Shape-controlled synthesis and surface plasmonic properties of metallic nanostructures. MRS Bull. 2005;30(5):338-348.

27. Ankanna S, Prasad T, Elumalai E, Savithramma N. Production of biogenic silver nanoparticles using Boswellia ovalifoliolata stem bark. Dig J Nanomater Biostruct. 2010;5(2):369-372.

28. Khan M, Adil SF, Tahir MN, et al. Green synthesis of silver nanoparticles mediated by Pulicaria glutinosa extract. Int $J$ Nanomedicine. 2013;8:1507-1516.

29. Kora AJ, Sashidhar RB, Arunachalam J. Aqueous extract of gum olibanum (Boswellia serrata): a reductant and stabilizer for the biosynthesis of antibacterial silver nanoparticles. Process Biochem. 2012;47(10):1516-1520.

30. Nabikhan A, Kandasamy K, Raj A, Alikunhi NM. Synthesis of antimicrobial silver nanoparticles by callus and leaf extracts from saltmarsh plant, Sesuvium portulacastrum L. Colloids Surf B Biointerfaces. 2010; 79(2):488-493.

31. Kim JS, Kuk E, Yu KN, et al. Antimicrobial effects of silver nanoparticles. Nanomedicine. 2007;3(1):95-101.

32. Lkhagvajav N, Yaşa I, Çelik E, Koizhaiganova M, Sari O. Antimicrobial activity of colloidal silver nanoparticles prepared by sol-gel method. Dig J Nanomater Biostruct. 2011;6(1):149-154.

33. Jain P, Sharma A. Antimicrobial activity of silver nanoparticles synthesized from Aspergillus species against common oral pathogens. J Chem Pharm Res. 2013;5(2):14-17.

34. Priyadarshini S, Gopinath V, Meera Priyadharsshini N, MubarakAli D, Velusamy P. Synthesis of anisotropic silver nanoparticles using novel strain, Bacillus flexus and its biomedical application. Colloids Surf B Biointerfaces. 2013;102:232-237.

35. Kanmani P, Lim ST. Synthesis and characterization of pullulan-mediated silver nanoparticles and its antimicrobial activities. Carbohydr Polym. 2013;97(2):421-428.

36. Gurunathan S, Han JW, Kwon DN, Kim JH. Enhanced antibacterial and anti-biofilm activities of silver nanoparticles against Gramnegative and Gram-positive bacteria. Nanoscale Res Lett. 2014;9(1): 373-373. 
37. Lara H, Ayala-Núñez N, Ixtepan Turrent L, Rodríguez Padilla C. Bactericidal effect of silver nanoparticles against multidrug-resistant bacteria. World J Microbiol Biotechnol. 2010;26(4):615-621.

38. Ansari MA, Khan HM, Khan AA, et al. Antibacterial activity of silver nanoparticles dispersion against MSSA and MRSA isolated from wounds in a tertiary care hospital of North India. Int J Appl Biol Pharm. 2011;2(4):34-42.

39. Amirulhusni AN, Palanisamy NK, Mohd-Zain Z, Ping LJ, Durairaj R. Antibacterial effect of silver nanoparticles on multi drug resistant Pseudomonas aeruginosa. World Acad Sci Eng Technol. 2012;6(7): 210-213.

40. Durán N, Marcato PD, Conti RD, Alves OL, Costa F, Brocchi M. Potential use of silver nanoparticles on pathogenic bacteria, their toxicity and possible mechanisms of action. J Braz Chem Soc. 2010; 21(6):949-959.

41. Jain J, Arora S, Rajwade JM, Omray P, Khandelwal S, Paknikar KM. Silver nanoparticles in therapeutics: development of an antimicrobial gel formulation for topical use. Mol Pharm. 2009;6(5):1388-1401.

42. Marius S, Lucian H, Marius M, et al. Enhanced antibacterial effect of silver nanoparticles obtained by electrochemical synthesis in poly(amide-hydroxyurethane) media. J Mater Sci Mater Med. 2011; 22(4):789-796.
43. Escobar-Chávez J, López-Cervantes M, Naïk A, Kalia Y, QuintanarGuerrero D, Ganem-Quintanar A. Applications of thermo-reversible Pluronic F-127 gels in pharmaceutical formulations. J Pharm Pharm Sci. 2006;9(3):339-358.

44. Thirumurugan G, Veni VS, Ramachandran S, Rao JV, Dhanaraju MD. Superior wound healing effect of topically delivered silver nanoparticle formulation using eco-friendly potato plant pathogenic fungus: synthesis and characterization. J Biomed Nanotechnol. 2011;7(5):659-666.

45. Prestes MA, Ribas CA, Ribas Filho JM, et al. Wound healing using ionic silver dressing and nanocrystalline silver dressing in rats. Acta Cir Bras. 2012;27(11):761-767.

46. Yates CC, Whaley D, Babu R, et al. The effect of multifunctional polymer-based gels on wound healing in full thickness bacteria-contaminated mouse skin wound models. Biomaterials. 2007;28(27):3977-3986.

47. Tian J, Wong KK, Ho CM, et al. Topical delivery of silver nanoparticles promotes wound healing. ChemMedChem. 2007;2(1):129-136.
International Journal of Nanomedicine

\section{Publish your work in this journal}

The International Journal of Nanomedicine is an international, peerreviewed journal focusing on the application of nanotechnology in diagnostics, therapeutics, and drug delivery systems throughout the biomedical field. This journal is indexed on PubMed Central, MedLine, CAS, SciSearch $®$, Current Contents $\AA /$ Clinical Medicine,

\section{Dovepress}

Journal Citation Reports/Science Edition, EMBase, Scopus and the Elsevier Bibliographic databases. The manuscript management system is completely online and includes a very quick and fair peer-review system, which is all easy to use. Visit http://www.dovepress.com/ testimonials.php to read real quotes from published authors. 